\title{
ABORDAGEM DADA \\ AO CONTEÚDO VARIAÇÃO \\ LINGUÍSTICA NA COLEÇÃO \\ DE LIVROS DIDÁTICOS \\ DE LÍNGUA PORTUGUESA \\ NOVAS PALAVRAS
}

\section{ENFOQUE DADO AL CONTENIDO DE LA VARIACIÓN LINGÜÍSTICA EN LA COLECCIÓN DE LIBROS DE TEXTO DE LENGUA PORTUGUESA NOVAS PALAVRAS}

\author{
THE APPROACH TO THE CONTENT OF LINGUISTIC VARIATION IN THE COLLECTION OF \\ PORTUGUESE LANGUAGE TEXTBOOKS NOVAS PALAVRAS
}

Priscilla Lacerda Júnior*

Maria de Lurdes Nazário**

Universidade Estadual de Goiás

RESUMO: O presente trabalho aborda o tratamento dado ao conteúdo variação linguística na coleção de livros didáticos de língua portuguesa Novas Palavras (2016) da Emília Amaral, Mauro Ferreira, Ricardo Leite e Severino Antônio. Tecemos nossa argumentação com base em estudos sobre ensino de língua numa abordagem sociointeracionista e nas orientações tecidas nos documentos oficiais para esse ensino, bem como em estudos da Sociolinguística e Ensino, que compreendem a língua como um sistema heterogêneo, devendo a escola promover uma educação linguística de valorização da pluralidade linguística brasileira. Esta é uma pesquisa qualitativa, estruturada em uma revisão bibliográfica e na análise de conteúdo da coleção de livros didáticos. Esta apresenta discussões teóricas necessárias no ensino do conteúdo variação linguística em dois capítulos do livro 1, porém nos capítulos que tratam de questões gramaticais mantém uma abordagem mais conservadora e normativista.

PALAVRAS-CHAVE: Abordagem Didática. Variação Linguística. Livro Didático.

RESUMEN: El presente trabajo aborda el tratamiento dado al contenido de la variación lingüística en la colección de libros de texto de lengua portuguesa Novas Palavras (2016) por Emília Amaral, Mauro Ferreira, Ricardo Leite y Severino Antônio. Tejemos nuestra argumentación basada en estudios sobre la enseñanza de la lengua en un enfoque socio-interaccionista y en las pautas tejidas en los documentos oficiales para esta enseñanza, así como en estudios de la Sociolingüística y Enseñanza, que comprenden el lenguaje

\footnotetext{
*Graduada em Letras (UEG), professorada educaçãobásica. E-mail:priscillalacerda1992@outlook.com.

** Doutora em Letras e Linguística, professora do curso de Letras da UEG, trabalha com estágio e PIBID. E-mail: mariadelurdesnazario@gmail.com.
} 
como un sistema heterogéneo, en el cual la escuela debe promover una educación lingüística para valorizar la pluralidad lingüística brasileña. Se trata de una investigación cualitativa, estructurada en una revisión bibliográfica y en el análisis de contenidos de la colección de libros de texto. Esta presenta discusiones teóricas necesarias en la enseñanza del contenido de la variación lingüística en dos capítulos del libro 1, sin embargo, en los capítulos que se tratan temas gramaticales se mantiene un acercamiento más conservador y normativista.

PALABRAS CLAVE: Enfoque Didáctico. Variación Lingüística. Libro de texto.

ABSTRACT: The present paper brings the treatment given to the content of linguistic variation in the collection of Portuguese language textbooks Novas Palavras (2016), by Emília Amaral, Mauro Ferreira, Ricardo Leite and Severino Antônio. We make up our argument based on studies on language teaching in a socio-interactionist approach and on the guidelines contained in the official documents for this teaching approach, as well as on studies on Sociolinguistics and Teaching, which understand that language is a heterogeneous system and hold that the school should promote a linguistic education of appreciation of Brazilian linguistic plurality. This is a qualitative study structured in bibliographic review and content analysis of the textbook collection. This paper presents theoretical discussions necessary to teaching the topics on linguistic variation in two chapters of the textbook 1 , however, the chapters dealing with grammatical issues maintain a more conservative and normative approach.

KEYWORDS: Didactic Approach. Linguistic Variation. Textbook.

\section{INTRODUÇÃO}

Neste texto, temos por objetivo discutir como o conteúdo variação linguística é abordado na coleção de livro didático (doravante LD) do ensino médio Novas Palavras (2016) de Emília Amaral, Mauro Ferreira, Ricardo Leite e Severino Antônio. Essa coleção está em sua $3^{a}$ edição, publicada no ano de 2016 pela editora FTD, e aprovada pelo Programa Nacional do Livro Didático (PNLD) 2018.

Compreendendo a escola como um espaço importante para os alunos terem acesso a conhecimentos necessários ao exercício de cidadania e o papel determinante dos LD nos processos de ensino-aprendizagem, é essencial levarmos em conta a seleção desse material e o tratamento dos conteúdos ali existentes, como o da variação linguística.

A experiência em sala de aula tem nos mostrado que, mesmo quando se tem um discurso de valorização das variedades linguísticas, a prática pedagógica e muitos materiais didáticos em geral ainda reforçam que o que vale mesmo é aprender a norma-padrão, com a valorização de uma prática de correção (superficial) dos usos não-padrão da língua portuguesa a todo custo.

Teoricamente baseamo-nos em estudos sobre ensino do português numa abordagem sociointeracionista (ANTUNES, 2003; TRAVAGLIA, 2009) e nas orientações tecidas nos Parâmetros Curriculares Nacionais de Língua Portuguesa do Ensino Médio (PCN+) (2002) e nas Orientações Curriculares do Ensino Médio (OCEM) (2006). Baseamo-nos também em estudos da Sociolinguística e Ensino, que compreende a língua como um sistema heterogêneo, devendo a escola promover uma educação linguística que valorize a pluralidade linguística brasileira e amplie o conhecimento que o estudante detém de seu idioma (BAGNO, 2004, 2007; GÖRSKI E COELHO, 2009; BORTONI-RICARDO, 2005; BORTONI-RICARDO et al., 2014).

Primeiro, analisamos a Introdução e algumas orientações dadas aos professores, presentes nos três volumes da coleção, procurando compreender a proposta didática assumida por seus autores. Em seguida, discutimos os capítulos Gramática... gramáticas... (capítulo 1) e Noções de variações linguísticas (capítulo 2), que se encontram na seção ${ }^{1}$ de Gramática do livro do $1^{\circ}$ ano (livro 1), já que é neles em que se centralizam as discussões referentes à heterogeneidade da língua portuguesa. Em seguida, fazemos uma análise de alguns tópicos gramaticais do livro do $2^{\circ}$ ano (livro 2) e do $3^{\circ}$ ano (livro 3), procurando compreender se o tratamento dado a esses conteúdos é coerente com o discurso construído nos capítulos do livro 1 que tratam diretamente da variabilidade da língua

${ }^{1}$ A organização dos conteúdos dessa coleção se faz em três seções: Literatura, Gramática e Leitura e Produção de Textos. 
enquanto conteúdo programático. Não temos a pretensão de esgotar aqui uma análise da coleção, mas problematizar alguns aspectos da abordagem já especificada.

\section{ENSINO DE LÍNGUA PORTUGUESA E CONCEPÇÕES IMPORTANTES NO CONTEXTO ESCOLAR}

A existência de uma crença que associa um juízo de valor ao que se considera certo e errado na língua fortalece e justifica comportamentos prescritivos na sociedade em geral. De acordo com Milroy (2011), essa crença é um efeito muito importante da padronização linguística, que leva ao desenvolvimento de uma consciência favorável à ideologia da língua padrão. Tudo isso se fortalece em discursos e práticas em busca da língua ideal, a que almejamos, às vezes, por todo custo. Conforme explica o autor, "essa crença assume a seguinte forma: quando houver duas ou mais variantes de alguma palavra ou construção, somente uma delas pode estar certa” (MILROY, 2011, p. 58).

Bortoni-Ricardo (2005, p. 16) discute há algum tempo justamente o fato de a cultura brasileira ser "pródiga nos comportamentos prescritivos em relação aos usos linguísticos"; comportamentos que se baseiam na ideologia citada, construída por gerações ao longo do tempo e fortemente arraigada entre nós. O ensino de português nas escolas brasileiras, que foi pensado e estruturado nesse contexto, se associa ainda, predominantemente, à concepção de língua imutável, vista como sistema, sendo a norma-padrão imposta a todos os contextos comunicativos.

Com esta visão, a atitude negativa das pessoas em relação a muitas variações linguísticas, inclusive nas escolas, se fortalece em meio a uma avaliação conservadora e até preconceituosa que impossibilita uma compreensão mais crítica de nossa realidade linguística e do ensino de português para falantes nativos.

Todo falante, escolarizado ou não, aprende regras de funcionamento de seu idioma que possibilitam seu uso nas interações diárias da vida. Porém, nas escolas, há muitos docentes que ignoram esse conhecimento e adotam uma postura pedagógica conservadora, considerando equivocado levar para a sala de aula conhecimentos construídos na área da Sociolinguística. Bagno (2007) alega que o fato de os PCN introduzirem conceitos provenientes dessa ciência na prática docente foi um ato muito positivo, mas que ainda é preciso ultrapassar barreiras, como a resistência das pessoas "presas" às práticas tradicionais de ensino e a falta de formação adequada dos professores.

Entretanto, a tessitura de outras práticas, com uma abordagem diferente da já consolidada nos contextos escolares, envolve ainda outros aspectos. Compreendemos que somente uma proposta de ensino que considere a natureza interacional da língua e sua variabilidade pode contribuir para que alternativas pedagógicas sejam objetivadas na escola.

Para isso, dependemos da compreensão de que todo texto se constrói na interação nos termos bakhtinianos (1990), como também de que é por meio de um dialogismo construído em sala de aula que a língua em funcionamento nesses textos pode ser significativamente ensinada e aprendida. Esse trabalho pressupõe o texto (e sua função social) como unidade de ensino, devendo ser lido e estudado considerando diferentes dimensões (linguística, textual, sociopragmática e discursivo e cognitivo-conceitual) (OCEM, 2006), em busca de construir assim uma abordagem sociointeracionista. Indo além desse processo a ser vivido na escola, o entendimento é de que

[...] é na interação em diferentes instituições sociais (a família, o grupo de amigos, as comunidades de bairro, as igrejas, a escola, o trabalho, as associações, etc.) que o sujeito aprende e apreende as formas de funcionamento da língua e os modos de manifestação da linguagem; ao fazê-lo, vai construindo seus conhecimentos relativos aos usos da língua e da linguagem em diferentes situações. Também nessas instâncias sociais o sujeito constrói um conjunto de representações sobre o que são os sistemas semióticos, o que são as variações de uso da língua e da linguagem, bem como qual seu valor social. (OCEM, 2006, p. 24) 
Nesse sentido, um trabalho escolar específico com essas variações de uso da língua e da linguagem, visa, entre outros objetivos, ampliar a competência comunicativa das pessoas, levando em conta o que realmente se diz e escreve no dia a dia dos usuários da língua. Assumir isso na escola é o mesmo que "admitir uma gramática também variável, flexível, adaptada e adequada às circunstâncias concretas em que a atuação linguística acontece" (ANTUNES, 2003, p. 90), já que "uma gramática de regras incondicionalmente rígidas" foge da realidade na qual a língua se efetiva (ANTUNES, 2003, p. 91).

Precisamos problematizar e compreender a heterogeneidade linguística (gramatical, lexical, semântica) como algo natural e comum a todo idioma. Como argumenta Bortoni-Ricardo ao falar dessa questão, não pode a escola "ignorar as diferenças sociolinguísticas"; professores e alunos "têm que estar bem conscientes de que existem duas ou mais maneiras de dizer a mesma coisa", compreendendo que "essas formas alternativas servem a propósitos comunicativos distintos e são recebidas de maneira diferenciada pela sociedade". (2005, p. 15).

É fundamental assim realizar um ensino dialógico e crítico, e não de reprodução e classificação da língua portuguesa. Antunes (2003) destaca justamente o quanto a escola desperdiça bastante tempo nomeando/rotulando as unidades do sistema linguístico, enquanto deveria privilegiar um estudo embasado na funcionalidade e aplicabilidade dessas unidades em textos orais e escritos, podendo construir assim uma abordagem sociointeracionista nesse ensino.

No âmbito dessa discussão, Antunes (2003) também nos lembra que a gramática de uma língua existe em virtude do que os indivíduos falam, ouvem, leem e escrevem nos atos sociais de comunicação por meio do idioma, argumentando que a gramática, por si só, não é capaz de aprimorar o desempenho comunicativo do sujeito.

Sendo assim, nós, professores, podemos pensar em algumas razões que tornam o trabalho com o conteúdo da variação linguística na escola de extrema importância. Primeira, devemos saber escolher a norma adequada à situação de comunicação; segunda, os textos lidos e produzidos ou não no contexto escolar estão recheados de fenômenos variáveis; terceira, a correção e a reescrita de texto na escola, quando existem, precisam se fundamentar em critérios de correção que problematizem a interferência da fala na escrita, a questão da variação no texto do aluno; quarta, a atitude linguística negativa que ocorre dentro e fora da sala de aula em relação aos falantes de variedades não-padrão e seus usos, contribuindo para a sua insegurança linguística.

Essas são algumas das razões que retratam bem o papel central da heterogeneidade linguística no ensino de português em nossas escolas. Obviamente, isso não significa que não devemos ensinar as regularidades do português padrão, mas discernir quais devem ser conteúdo na escola e como ensiná-las, tendo em vista um trabalho que conceba a língua portuguesa como forma de interação e como um sistema variável, a fim de construir uma abordagem de ensino que lide verdadeiramente com a funcionalidade dos elementos linguísticos nos textos.

Pensando nisso, recorremos a Travaglia (2009) justamente por este argumentar que desenvolver a competência comunicativa dos usuários da língua materna deve ser o principal objetivo desse ensino. Isso quer dizer que a escola precisa se atentar para o aprimoramento da capacidade dos alunos de empregá-la nas mais diversas situações de comunicação. Para alcançar tal finalidade, o autor afirma que é fundamental "propiciar o contato do aluno com a maior variedade possível de situações de interação comunicativa por meio de um trabalho de análise e produção de enunciados ligados aos vários tipos de situações de enunciação" (TRAVAGLIA, 2009, p. 18).

Por isso, compreender como o professor concebe a linguagem/língua é uma questão que merece atenção. Para Travaglia (2009), a concepção que o professor tem "da natureza fundamental da língua altera em muito o como se estrutura o [seu] trabalho com [ela] em termos de ensino." (p. 21). Podemos inferir que a ineficiência aí, muitas vezes, se explica também pelas percepções anacrônicas e deturpadas detidas por todos nós acerca dos fenômenos linguísticos.

Sobre essa questão, Antunes (2003) também compreende o quanto tudo que se realiza em sala de aula depende em muito dessa concepção do docente. Para esta pesquisadora, a definição dos objetivos, a seleção dos objetos de estudo, a escolha dos 
procedimentos metodológicos, enfim, todo o processo de ensino-aprendizagem é determinado por um conjunto de princípios teóricos e pela concepção de linguagem/língua do professor.

Se o ensino de hoje ainda apresenta forte viés tradicional, sendo baseado em nomenclatura e classificação, é porque em sociedade, e assim na escola, esse aprendizado é prioridade, sendo visto como um meio para se "falar e escrever bem".

Como explica muito claramente Ferreira (2004), a busca pelo "domínio metalinguístico é visto como fundamental para o aprendizado da língua" (p. 69). De maneira que, para muitos docentes, "o saber sobre a língua interessa mais do que o uso da linguagem em situações concretas de interlocução." (p. 69). Nesse percurso conservador de concepções já questionadas nos estudos linguísticos, mas de práticas tradicionais mantidas/repetidas/seguidas de modo geral no contexto escolar, "o uso lingüístico é quase sempre avaliado em termos do 'certo' e do 'errado', desconsiderando-se a capacidade que o aluno tem de empregar [seu idioma] das mais diversas formas e com os mais diferentes propósitos e resultados.” (FERREIRA, 2004, p. 69).

\section{A VARIAÇÃO LINGUÍSTICA NOS LIVROS DIDÁTICOS DE LÍNGUA PORTUGUESA}

Considerando a argumentação apresentada, a exigência então por materiais didáticos com uma base teórica consistente sobre variação linguística e atividades reflexivas, como os LD tão presentes em sala de aula, torna-se ainda mais fundamental.

Entretanto, para Bagno (2007), o tratamento que os LD brasileiros dão a esse conteúdo ainda é um tanto problemático. O autor justifica que em muitas coleções "[...] a confusão no emprego dos termos e dos conceitos prejudica muito o trabalho que se faz nessas obras em torno dos fenômenos de variação e mudança" (BAGNO, 2007, p. 119).

Uma das críticas do linguista se refere à insistência de exemplificar variações da língua portuguesa com tirinhas protagonizadas por caipiras, especialmente do Chico Bento, com samba de Adoniran e poema de Patativa de Assaré. Outro questionamento pertinente recai sobre as explicações e as atividades desses livros focalizadas em reescrever tais textos, a fim de passá-los para a norma culta, desconsiderando a identidade sociocultural de Chico Bento, por exemplo.

Em sua argumentação o autor explica que esses textos não são representações autênticas das variedades linguísticas, mas sim representam "uma intenção lúdica, artística, estética e, nem de longe, um trabalho científico rigoroso" (BAGNO, 2007, p. 120), deixando evidente a incoerência dessas escolhas didáticas. Nesse sentido, a preocupação se deve especialmente à exposição de uma base teórica e exemplificações inconsistentes para composição dos materiais didáticos, o que implica numa limitação do tratamento dado ao conteúdo ou ainda em um tratamento equivocado.

Bagno (2007) ainda alega que "[...] é muito frequente, nos materiais didáticos, a abordagem da variação linguística se restringir a fenômenos que poderíamos chamar de superficiais: o sotaque e o léxico" (p. 132), seja de região para região do Brasil ou do português brasileiro para o português europeu. Nas palavras do autor,

Existe um nível mais profundo de variação linguística que em geral é pouco abordado: a variação morfossintática, ou seja, os usos diferenciados que cada grupo social faz dos recursos gramaticais da língua. E são alguns desses fenômenos morfossintáticos variantes que deveriam se tornar o foco principal da educação em língua materna [...] (BAGNO, 2007, p. 132, grifo do autor).

Considerando as dificuldades apresentadas por nossos alunos no aprendizado da escrita padrão, na aquisição de novos usos da língua, é fundamental tratar da variação morfossintática tão recorrente nos diversos textos produzidos (orais e escritos) no contexto escolar. Deveria ser verdadeiramente um procedimento, seguindo o que orienta as OCEM (2006, p. 82), "[...] aplicar os conhecimentos relativos à variação linguística [...] na produção de textos" dos alunos, em busca de ampliar o que sabem do idioma. 
Daí a importância de questionarmos o tratamento dado a esse conteúdo nos LD, não nos conformando apenas com o fato de ele constar no sumário dessas obras quase que para cumprir as exigências do PNLD, compondo a lista de obras que serão compradas e distribuídas nas escolas; como também não nos conformando com um tratamento teórico e didático inconsistente e/ou superficial.

O entendimento é de que, tendo o LD um "[...] importante papel no contexto escolar e, mais especificamente, no estudo da língua", esse material "[...] deve colaborar na ampliação do repertório linguístico e no desenvolvimento da competência linguística do estudante" (SANTOS; BORGES, 2011, p. 1015). Com esse propósito, esse material precisa fortalecer o fazer pedagógico do professor, que pode não deter conhecimentos dos estudos sociolinguísticos e ensino. E isso significa, entre outras demandas, propor nas situações de recepção e produção textual a problematização e a compreensão da heterogeneidade da língua portuguesa e das escolhas linguísticas feitas, especialmente, pelo nosso alunado.

\section{DISCUSSÃO DO TRATAMENTO DADO AO CONTEÚDO DE VARIAÇÃO LINGUÍSTICA NA COLEÇÃO NOVAS PALAVRAS (2016)}

Considerando a Apresentação da coleção feita no livro 1, os autores iniciam se comprometendo a convidar continuamente os alunos a refletirem sobre as habilidades de falar, ler e escrever, por meio de um trabalho com variados textos a fim de aprimorar a sua produção textual. Comprometem-se com a reflexão a respeito das "diferentes maneiras de falar e de escrever" que se "desenvolverão com o estudo das estruturas que estabelecem a organização e o sentido dos textos que constituem o nosso 'mundo de leitura" (livro 1, p. 03). Finalizando, conclamam-nos para transformar o livro em um parceiro de aprendizagem, assumindo um posicionamento ativo nesse processo, sendo assim conquistadas "novas habilidades de uso da linguagem" (livro 1, p. 03).

Dessa forma, a expectativa criada é de um trabalho com os usos que diversos falantes (entre eles, nossos alunos) fazem da língua nos diferentes gêneros textuais (orais e escritos). Os autores não utilizam na Apresentação a construção aprendizado da norma padrão ou da norma culta, mas nos direcionam a pensar, ao falarem na conquista de "novas habilidades de uso da linguagem", no ensino de diferentes normas; um resultado que deve ser alcançado, entendemos, por meio de um trabalho efetivamente reflexivo e crítico dos diferentes usos linguísticos em seus contextos comunicativos. Como bem defende Bortoni-Ricardo et al. (2014), "A introdução de novos padrões linguísticos deve ser feita [na escola] com uma metodologia que contemple as diferenças de usos...” (p. 131), construindo assim uma educação linguística que amplie a competência comunicativa do aluno.

A preocupação com esse aprendizado é explicitada também na seção Conversa com o professor no final do livro 1 (p. 353), quando há a definição de alguns objetivos esperados para o ensino de gramática, sendo que dois deles são centrais para a nossa discussão: "contribuir para que os alunos desenvolvam uma visão não preconceituosa em relação às variedades linguísticas divergentes da variedade padrão" e "possibilitar que [...] ampliem gradativamente seu domínio de uso da variedade padrão, modalidade linguística indispensável para sua participação na vida social letrada e para sua futura vida profissional” (p. 361).

Já na seção O encaminhamento didático dos conteúdos (p. 362; final do livro 1), os autores deixam claro que optaram ora por uma abordagem prescritiva no ensino da língua portuguesa, "tanto na exposição teórica como nos exercícios", ora por uma descritiva, considerando sempre "as especificidades do tópico gramatical tratado" (p. 362). Explicam a partir daí que depois da exposição teórica de cada conteúdo, os exercícios são divididos em duas seções, a de Atividades e a de Da teoria à prática (seção dividida em três subtítulos Ponto de Partida, Agora é sua vez e E Mais...).

Na seção denominada Atividades, "visam à fixação dos conceitos e da terminologia apresentados na exposição teórica”, informando que aí adotam uma abordagem mais tradicional para o trabalho com gramática, com atividades "de resoluções mais rápidas". Justificam essa escolha, que acaba por fortalecer o ensino de nomenclatura e classificação, argumentando ser uma perspectiva que tem “representatividade em processos de seleção aos cursos superiores” (p. 362).

Explicam que caberá ao professor decidir a partir das expectativas de seus alunos se dará "maior ou menor ênfase" às propostas dos exercícios. Nesse caso, esse ensino pode ficar submetido em muito não só a concepções mais conservadores de professores e alunos, 
como também sofrer com as consequências de uma formação acadêmica que de fato não preparou o docente para trabalhar com a variação linguística e os tópicos gramaticais numa abordagem mais reflexiva e funcional.

Já na seção Da teoria à prática, os autores expõem que as atividades focalizam o uso dos elementos gramaticais estudados como recursos linguísticos comunicativos, analisando questões textuais e/ou discursivas, e aspectos práticos e funcionais dos elementos linguísticos nos textos. São propostas nessa seção pesquisas de campo de alguns fenômenos linguísticos. Ressaltamos aqui a importância das propostas de pesquisa de campo de fenômenos variáveis da língua portuguesa falada no Brasil, sendo algumas discutidas mais à frente.

Vejamos, então, como os autores abordam as variedades e suas variantes, os falantes e seus usos, como ocorrem as explicações sobre o conteúdo em questão e algumas das atividades propostas. $\mathrm{Na}$ análise, procuramos compreender se a variação linguística se encontra na obra mais atendendo a uma orientação dos documentos curriculares ou se a abordagem dada vai além, problematizando esse ensino de modo a ampliar efetivamente os conhecimentos e as habilidades de uso da língua por parte do aluno.

É preciso dizer que na seção Conversa com o professor no final de todos os livros, há orientações específicas sobre os objetivos do estudo de cada conteúdo, sugestões de procedimentos e de atividades. Não abordamos na análise essa seção, que é direcionada somente ao professor.

\subsection{DISCUTINDO O LIVRO 1 - GRAMÁTICA E VARIAÇÃO LINGUÍSTICA}

Iniciamos a análise com o capítulo intitulado Gramática... gramáticas do livro 1 (p. 129), que apresenta e discute a concepção de gramática da língua, levando os alunos a refletirem sobre seu conhecimento linguístico. O plural da segunda palavra do título direciona o raciocínio para o fato de que existem diferentes gramáticas e muitas regras gramaticais em uma mesma língua. E os autores introduzem o tema questionando exatamente: "No título do capítulo, talvez você tenha estranhado um pouco o plural 'gramáticas'. Afinal... existe mais de uma 'gramática'?” (p. 131). Ao levantarem essa questão, pedem ainda ao aluno que "Não se surpreenda" com o fato de dominarmos "mais de mil regras gramaticais" (p. 131).

Em materiais didáticos ou em sala de aula, geralmente, não se aborda essas questões; talvez justamente por falta de compreensão das concepções de gramática ou pelas limitações que uma abordagem tradicional imprime sobre as aulas de português. É comum em nossa sociedade a visão de que só a norma-padrão é regida por regras, só ela tem gramática.

Sendo assim, com essa discussão inicial proposta nesse capítulo, os autores avançam no debate sobre a variabilidade linguística na escola, contribuindo para a compreensão por parte do aluno de que ele já tem uma competência linguística e de que seus usos nãopadrão são regidos por regras gramaticais, assim como aquelas que lhe são apresentadas na própria coleção.

Pensando então na construção desse conhecimento, é importante a distinção feita na página 133 entre gramática internalizada e gramática normativa, em que aquela é conceituada como um sistema de funcionamento interno que se dá pela prática diária dos falantes e esta como um conjunto de normas/orientações "para se falar/escrever em situações formais de comunicação”.

Gramática internalizada

Sistema de regras que constituem a estrutura de funcionamento da língua $e$ que são assimiladas naturalmente pela prática - por todos os falantes do idioma.

\section{Gramática normativa}

Teoria que, tomando como referência os usos tradicionais do idioma, descreve e propõe um conjunto de normas e orientações para se falar/escrever em situações formais de comunicação.

Figura 1: Concepções de Gramática (livro 1)

Fonte: Amaral et at. (2016, p. 135) 
Por outro lado, ao falarem sobre o sistema de regras da língua que "são assimiladas naturalmente - pela prática - por todos os falantes do idioma", perdem a oportunidade de incluir textos e propor discussões que deixem claro que cada variedade linguística se caracteriza por usos que identificam os falantes de uma comunidade de fala. Seria um momento para problematizarem a questão da avaliação social e do preconceito linguístico que os usuários sofrem por fazerem uso de variantes não-padrão. Essa discussão é relevante para que os alunos tenham uma consciência mais fundamentada sobre a gramaticalidade das diferentes variedades, que contribuem para a identificação da origem social e regional dos indivíduos.

Ao discutirem ainda sobre o conceito de gramática introduzem os adjetivos válida e inválida para se referirem a estruturas sintáticas na perspectiva da gramática normativa $(\mathrm{GN})$ e da gramática internalizada (GI), com os exemplos: Os dois rolô no chão (inválida para a GN; válida para a GI) / Os dois rolaram no chão (válida para a GN e GI) (livro 1, p. 135). Parece-nos uma tentativa mal sucedida de fugir do uso de certo x errado tão questionado pelos linguistas e muitos professores. Ao dizerem que Os dois rolô no chão é inválida na perspectiva normativista, recaímos na mesma avaliação, que é social e não linguística, da dicotomia certo/errado. De qualquer modo, na coleção os termos certo e errado são pouco usados, e quase sempre entre aspas, explicitando a crítica já construída a essa avaliação.

A escolha dos adjetivos válido/inválido ainda tem outro problema. São utilizados tanto na acepção de não aceito pela gramática normativa quanto na de uma estrutura frasal gramatical ou agramatical, como ocorre na página 139 (livro 1):

\section{- Gramática internalizada \\ Sistema de regras próprias do idioma que comandam sua estrutura e funcionamento e determinam se uma construção é ou não linguisticamente válida. Exemplos: \\ "Chega-se a Marte, mas não se chega ao próximo." (J. Saramago) $\rightarrow$ válida \\ Ao chega-se Marte mas a próximo chega não se. $\rightarrow$ inválida}

Figura 2: Exposição teórica sobre concepções de gramática (livro 1)

Fonte: Amaral et at. (2016, p. 139)

Ao retomarem o conceito de gramática internalizada no fechamento do capítulo classificam "Chega-se a Marte, mas não se chega ao próximo" como uma construção válida (como sinônimo de gramatical) e "Ao chega-se Marte mas a próximo chega não se" como uma construção "linguisticamente inválida" (como sinônimo de agramatical). Nessa explicação, não é teoricamente correto usar as categorias válida/inválida, mas sim explicar que há construções que são gramaticais na língua, isto porque são realizáveis; e, por conta disso, podemos então pensar naquilo que não ocorre, classificado como agramatical ("Ao chega-se Marte mas a próximo chega não se").

Ainda no capítulo 1 (livro 1), os autores apresentam explicações teóricas importantes para a compreensão do português como um conjunto de variedades linguísticas, detalhando o conceito de norma-padrão e de variedade (culta formal e culta informal; nãopadrão, coloquial ou popular); informam que a norma-padrão é estabelecida a partir da culta formal, apesar de não discutirem sobre qual seria essa variedade culta (p. 136-137); explicam, mas em poucas palavras, que as variedades cultas do português são "típicas de falantes urbanos de maior nível de escolaridade e de maior influência social” (137), sendo chamadas de normas urbanas de prestígio.

Nesse momento, é ressaltada a importância do contexto em que é desenvolvida a comunicação, conforme orientações dos PCN+ de Língua Portuguesa (2002) para o ensino médio, onde se lê que é fundamental levar em consideração a situação de produção dos discursos, a fim de compreender as particularidades do idioma tanto em práticas orais quanto escritas. Explicam ainda sobre a adequação e a inadequação linguística, destacando fatores que influenciam as escolhas linguísticas dos falantes, como a relação falante-ouvinte, a situação comunicativa, o assunto, o ambiente, a intencionalidade, o gênero textual e o suporte escolhido para fixar o texto.

Já no capítulo 2, Noções de variações linguísticas (livro 1, p. 158), logo no início, há um pequeno quadro explicativo na margem do livro, com a indagação para que saber que a língua apresenta variações. Em resposta ao questionamento, os autores problematizam 
que esse conhecimento, além de nos permitir comunicar de "maneira mais adequada e eficiente ao falar/ouvir e ao escrever/ler" (p. 159), contribui para a discussão do preconceito linguístico. No entanto, apesar dessas colocações, não há uma discussão mais aprofundada ou textos sobre preconceito linguístico, sobre as atitudes negativas de muitos de nós diante das diversas variantes estigmatizadas do português falado e escrito no Brasil, inclusive na escola; ambiente onde essa reflexão deveria ser produzida e fortalecida.

Os autores então caracterizam os quatro tipos de variação (sociocultural, situacional, histórica e geográfica), conhecimento que nos leva a pensar sobre a heterogeneidade linguística existente em nosso país e nos contextos sociais e regionais demarcados também pela língua.

Para expor especificamente sobre a variação sociocultural, na página 159, utilizam o texto Só os óio de Cornélio Pires; jornalista que, conforme informações do próprio livro, "se dedicou a pesquisar, registrar e divulgar a cultura sertaneja e o modo de vida do caipira" (livro 1, p. 159). Os autores falam de diferenças entre o falar do sertanejo (variedade coloquial) e do narrador-personagem (variedade culta), mas não discutem objetivamente nenhum fenômeno linguístico.

\section{Só os óio}

Ao regressar de Mineiros, em Goiás, [...] perdemos a hora de atravessar o Rio dos Bois.

Não houve rogos nem promessas que demovessem o balseiro de sua resolução. Eram mais de seis horas e não daria passagem. Tocamos rastro atrás cinco léguas e fomos pedir pouso em casa de um sertanejo pobre, casa de pau a pique [...].

Estávamos em julho e o frio era intenso.

Ao pedir o pouso, o caipira perguntou:

- Vacê trôxe rede?

- Não.

- Curchuádo?

- Também não.

- E cuberta?

- Também não trouxe.

- Aãã... Intãoce vacê, de durmi, só trôxe os óio?

PIRES, Cornélio. Patacoadas: anedotas: simplicidade e astúcias de caipiras. Itu: Ottoni, 2002. p. 71. (Conversa caipira).

Figura 3: Texto Só os óio para discussão de variação sociocultural (livro 1)

Fonte: Amaral et at. (2016, p. 157)

Argumentam que o linguajar do sertanejo é típico de uma parcela mais pobre da sociedade, pessoas que geralmente moram longe dos centros urbanos e não frequentaram a escola ou tiveram "uma escolarização irregular, precária e de baixa qualidade." (p. 160); e que o narrador-personagem emprega uma variedade que nos faz concluir que ele frequentou a escola, manteve mais contato com os meios de comunicação (como livros, jornais, revistas) e conviveu com pessoas de nível cultural formal mais elevado.

Exposições e exemplificações assim reduzem a compreensão das variedades linguísticas, já que geralmente as produções dos sertanejos são exploradas para evidenciar a variedade coloquial-popular, enquanto o português culto aparece na fala daqueles que (provavelmente) moram na cidade, onde muitos julgam encontrar os portadores da língua "certa". Como argumenta Bagno (2007), "parece estar por trás dessa tendência a suposição (falsa) de que os falantes urbanos e escolarizados usam a língua de um modo mais 'correto', mais próximo do padrão, e que no uso que eles fazem não existe variação” (p. 120).

Ao citarem, por exemplo, na coleção, a fala de um advogado enunciada num tribunal ("Senhoras e Senhores, aceitemos a verdade: a testemunha nada acrescentou aos fatos já conhecidos por todos”) (p. 160) e depois a sua fala informal enunciada em um bar (“Caras, 
vamos cair na real: a testemunha só enrolou”) (p. 160), não há como não pensar que é comum esse tipo de profissional figurar justamente no exemplo de variação situacional.

Observemos que a fala informal desse advogado se caracteriza por uso de gíria e expressões coloquiais, como se a ausência de concordância nominal ("só trôxe os óio"), a redução do fonema ("cuberta") e a monotongação ("trôxe"), que aparecem na fala do sertanejo acima, não pudessem ocorrer na fala de um advogado ou qualquer outro profissional com nível superior de escolaridade; como se um falante do português brasileiro falasse "enrolou" e não "enrolô".

Ao tecerem essas explicações, chama-nos a atenção também a ausência de discussão de variantes que caracterizam cada um dos tipos de variação nos diferentes níveis de análise da língua. Só tratam direta e explicitamente das variantes lexicais na variação geográfica, explorando as formas pipa x pandorga ou papagaio, tapioca, maranhão, arraia, quadrado. Não são discutidos assim exemplos dos níveis fonético-fonológico, semântico ou morfossintático tanto no português culto como no português coloquial ou popular, tratando esse conteúdo de modo superficial.

No subtítulo A língua portuguesa - origens e geografia (p. 164-166), os autores contribuem com informações e discussões sobre a origem e a expansão do português pelo mundo. Entretanto, tratam inconsistentemente as diferenças linguísticas entre o português de Portugal e o português brasileiro, por exemplificarem os usos de portugueses e brasileiros somente no nível lexical ("bica” para "cafezinho"; "peúgas" para "meias"; "canalizador" para nosso "encanador"), também não abordando diferenças morfossintáticas importantes que se consolidaram desde o período colonial no Brasil.

\subsection{A COERÊNCIA ENTRE A ABORDAGEM DADA AO CONTEÚDO VARIAÇÃO LINGUÍSTICA E O ENSINO DE ALGUNS CONTEÚDOS GRAMATICAIS NA COLEÇÃO NOVAS PALAVRAS (2016)}

Discutiremos aqui a abordagem dada a alguns fenômenos gramaticais da língua portuguesa que sempre estão envolvidas em processos de variação linguística: pronomes pessoal e demonstrativo no livro 2; concordância nominal, concordância verbal, regência e colocação pronominal no livro 3. Procuramos compreender se tal abordagem é coerente com o discurso sobre a variabilidade da língua construído nos capítulos do livro 1.

No livro 2, observamos a exposição teórica dos pronomes pessoais (p. 154), momento em que os autores apresentam o seguinte paradigma pronominal:

\begin{tabular}{|l|l|l|}
\hline 1. pessoa & $\begin{array}{l}\text { do singular } \\
\text { do plural }\end{array}$ & $\begin{array}{l}\text { eu, me, mim, comigo } \\
\text { nós, nos, conosco } \\
\text { tu, te, ti, contigo } \\
\text { você, o/a, se, si, consigo, lhe }\end{array}$ \\
\hline 2. pessoa & do singular & $\begin{array}{l}\text { vós, vos, convosco } \\
\text { vocês, os/as, se, si, consigo, lhes }\end{array}$ \\
\hline do plural & do singular & ele/ela, o/a, se, si, consigo, lhe \\
\hline do plural & eles/elas, os/as, se, si, consigo, thes
\end{tabular}

Figura 4: Pronomes Pessoais (livro 2)

Fonte: Amaral et at. (2016, p. 157)

Analisando o quadro acima, vemos que a variante "você" (2a pessoa) é adicionada ao paradigma pronominal dos pronomes pessoais que é reconhecido como padrão. Os autores chamam inclusive nossa atenção ao discutirem que, na variedade coloquial-popular, a conjugação verbal de "tu" e de "você" não difere uma da outra, ao contrário do que prescreve a gramática normativa, pois a maioria dos falantes emprega os dois pronomes com o verbo em $3^{\text {a }}$ pessoa. Vejamos os exemplos dados no livro: 


\section{- Sei que tu pesquisaste bem esse assunto. $\rightarrow$ variedade culta \\ - Sei que tu pesquisou bem esse assunto. $\rightarrow$ variedade coloquial-popular \\ - Sei que você pesquisou bem esse assunto. $\rightarrow$ variedades culta e coloquial-popular}

Figura 5: Conjugações dos pronomes TU e VOCÊ (livro 2)

Fonte: Amaral et at. (2016, p. 157)

Muito embora essa explanação nos alerte para duas variantes (tu/você), é uma questão colocada como um adendo à explanação teórica do conteúdo pronomes pessoais, não representando de fato muito espaço para a discussão dos usos desses pronomes no Brasil. O intuito dos autores é mais declarar uma informação, nos lembrando do uso do singular/plural, que é uma colocação muito relevante para ser trabalhada em sala de aula, mas sem problematizar esse fenômeno de variação nas práticas linguísticas dos brasileiros. Seria um momento importante para tecer reflexões sobre as crenças e a avaliação de todos nós sobre os usos desses dois pronomes em diferentes regiões do país.

Questionamos ainda a opção por não haver explicações sobre a variação que há entre nós $x$ a gente, a conjugação variável de $a$ gente vai/a gente vamos, apesar de os autores reconhecerem o uso de a gente por todos os brasileiros há anos como pronome pessoal, mas explicando que “oficialmente’ não integra a classe dos pronomes” (livro 2, p. 158).

De outro lado, a coleção traz um texto do linguista John Schmitz (livro 2, p. 158) a respeito do percurso histórico de surgimento do uso do pronome "você" e da expressão "a gente" como pronome. Esse texto chama a atenção para fatores importantes do desenvolvimento da língua portuguesa no Brasil que ajudam o professor a ensinar sobre o fenômeno da mudança linguística, que inclui compreender o porquê de usarmos "você".

Ainda pensando na problematização do uso dos pronomes "você" e "a gente", já se sabe que eles requerem uma conjugação em $3^{a}$ pessoa, provocando "uma reestruturação no paradigma verbal, que passa de seis formas básicas para três" (GÖRSKI \& COELHO, 2009, p. 85), conforme visualizamos abaixo.

\begin{tabular}{c|c}
\multicolumn{2}{l}{ Tabela 1: Descrição dos paradigmas pronominais tradicional e em uso } \\
Paradigma 1 & Paradigma 2 \\
\hline Eu ando & Eu ando \\
\hline Tu andas & Tu anda (s)/ você anda \\
\hline Ele (a) anda & Ele (a) anda \\
\hline Nós andamos & Nós anda(mos)/ a gente anda \\
\hline Vós andais & Vocês andam \\
\hline Eles (as) andam & Eles/as andam
\end{tabular}

Na tabela, enquanto de um lado temos a norma-padrão das conjugações verbais, de outro, temos o padrão de uso dos falantes de português, constituindo-se em um outro paradigma pronominal. Considerando que a concordância verbal é uma das grandes dificuldades dos alunos no aprendizado da norma-padrão, o debate desses paradigmas é pertinente em sala. As propostas difundidas em diversos estudos sobre ensino de língua portuguesa não têm a finalidade de contribuir para uma prática em sala de aula que exclua um dos paradigmas flexionais verbais, mas que trabalhe com ambas as possibilidades. Com isso, o professor pode explorar o conhecimento internalizado da língua que o aluno detém a fim de este aprender mais. 
Obviamente, a conjugação padrão é extremamente importante na formação linguística dos alunos, devendo ser ensinada nas escolas. Entretanto, não sem discutir a redução na conjugação verbal, focalizando os diversos usos estigmatizados (às vezes, imperceptíveis para alguns usuários) de não concordância verbal que ocorre na fala e na escrita. É preciso debater com os discentes as ocorrências dessas variantes linguísticas em seus textos, a fim de promover conhecimento que contribua no momento de recepção e produção textual. É preciso ainda refletir sobre o valor social das normas (padrão, culta e coloquial-popular), pensando em uma educação linguística que dê mais chances de as pessoas aprenderem mais e de modo crítico, opondo-se a um ensino que categoriza interferências da fala na escrita como erro simplesmente.

Seguindo com a análise, na página 160 (livro 2), há uma questão importante de variação que ganha uma apresentação teórica e proposta de discussão mais consistentes: o emprego dos pronomes ele(s)/ela(s) como complementos verbais não precedidos de preposição, como em: "Ontem de manhã, convidei elas para a festa de Natal em nossa casa" (grifo nosso) - categorizado como um uso coloquial-popular.

Além de explicações sobre o emprego das formas $o(s) / a(s)$ (variedade culta) e ele(s)/ela(s) (variedade coloquial-popular) na função de complemento do verbo (objeto direto) serem colocadas lado a lado na página 160, há, no subtítulo E Mais... (p. 183-184), uma proposta de atividade de pesquisa de campo com o objetivo de discutir as ocorrências das formas $o(s) / a(s), l o(s) / l a(s)$ e ele(s)/ela(s) na função de complemento verbal sem preposição. A atividade pede a gravação de falas, a seleção de trechos com as formas estudadas, a transcrição dos trechos e a tabulação dos dados, com a apresentação dos resultados e a discussão coletiva, orientadas pelas seguintes questões para cada grupo de alunos:

\section{Apresentação dos resultados e discussão coletiva}

a) Em data a ser definida, os grupos entregarão ao(à) professor(a) as transcrições dos trechos selecionados. Oralmente, responderão aos demais colegas os dois itens da pergunta a seguir, apresentando, quando for o caso, o fragmento em que a ocorrência foi registrada:

Foi documentado algum caso em que, por conta das características socioculturais do falante e da situação de comunicação:

- o emprego de ele/a, em lugar de o/a, ficou inadequado? Por quê?

- o emprego de o/a soou meio "artificial", pedante? Por quê?

b) Com a orientação do(a) professor(a), será preparada, então, uma tabela geral dos dados. A turma poderá analisar coletivamente se, nos limites da pesquisa, esses dados confirmam o que diz o professor Marcos Bagno no texto da primeira parte desta atividade.

Figura 6: Atividade de pesquisa de campo (livro 2)

Fonte: Amaral et at. (2016, p. 184)

A proposta de pesquisa de campo é tecida com base em um texto de Marcos Bagno retirado do livro Preconceito Linguístico (1999 apud AMARAL et al., 2016), no qual o linguista discorre sobre o fato de $o(s) / a(s)$ serem pronomes "praticamente extintos no português falado do Brasil", aparecendo somente "em situações de uso mais formais, quando o falante quer deixar claro que domina as regras impostas pela gramática escolar” (p. 183).

Escolhas didáticas assim promovem a articulação da teoria às práticas linguísticas vivenciadas pelos alunos, levando à reflexão e ao aprendizado dos usos possíveis das formas em questão. A proposta também contribui inevitavelmente para o debate das características socioculturais dos falantes e dos contextos comunicativos, num processo mais significativo de estudo da língua.

Já ao tratarem do pronome demonstrativo (livro 2, p. 168), os autores tecem uma explicação incompleta ao dizerem somente ser comum, "mesmo na língua culta, a substituição de 'este/esta' por 'esse/essa' para indicar elementos textuais que ainda serão referidos no texto” (p. 169). Analisando o uso desse pronome no português brasileiro, qualquer discussão deveria explicitar que é habitual, é comum o uso do demonstrativo "esse" em ambientes de imposição normativa do "este". 
Sendo esse fenômeno alvo de correção por parte dos professores nos textos escritos dos alunos, que usam "esse" em lugares em que a gramática normativa impõe o uso do "este", é mais que relevante demonstrar que os estudos têm concluído que selecionamos no Brasil o paradigma "esse/este" X "aquele", tanto no português culto quanto no popular. As pesquisas explicam ainda que esse fenômeno se dá por conta de uma perda da "distinção lexicalmente marcada entre primeira e segunda pessoa" (p. 207). Esse fenômeno fez com que "este" e "esse" passassem a ser usados para "indicar objetos próximos ou para retomar informações próximas" (p. 207), em que "este" e "esse" têm a mesma função referencial (CASTILHO, 2010).

Já no capítulo de Concordância Nominal (livro 3), na exposição teórica não há explicação sobre a questão da variação no uso da concordância. Tece-se somente um comentário de cinco linhas sobre "palavras que podem causar dúvidas quanto à concordância", citando obrigado, anexo, incluso, meio, mesmo, bastante, caro, barato, só (p. 228), mas sem debater sobre o contexto de ocorrência desses usos.

Por outro lado, na seção Da teoria à prática, há um exercício (p. 233) com base no texto Meio-dia e meia de Rubem Braga, no qual é focalizada uma crítica de valorização de variantes não-padrão de concordância nominal. Nesse texto, Rubem Braga defende um posicionamento diferente, não prescritivo, diante de usos como "meio-dia e meio" e "estou meia triste". Em suas palavras "a língua da gente não tem apenas regras: tem um espírito, um jeito, uma pequena alma que aquele 'meio-dia e meia' faz sofrer. E, ainda que seja errado, gosto da moça que diz: 'Estou meia triste...' Aí, sim, pelo gênio da língua, o 'meia’ está certo” (BRAGA, 1984, p. 58 apud AMARAL et al., 2016).

Ainda tratando da concordância nominal, no subtítulo E Mais... é solicitada outra pesquisa de campo, agora, para analisar a concordância de gênero e número do artigo com o substantivo. A proposta, que é interessante, orienta a gravação de trechos de fala (entrevistas feitas pelo grupo ou gravação de programas de rádio ou TV) de falantes de diferentes escolaridades (ensinos fundamental, médio e superior). Em seguida, devem identificar casos em que há ou não a concordância entre artigo e substantivo, para compor uma tabela na qual os dados estarão separados por nível de escolaridade.

No entanto, considerando que não há textos ou uma exposição teórica mínima sobre esse tipo de variação, compreendemos que a discussão resultante da pesquisa, a partir da tabulação dos dados, pode ficar prejudicada. A compreensão do resultado obtido, do seu significado numa perspectiva social e linguística, depende de conhecimentos sociolinguísticos prévios sobre a questão.

No capítulo de Concordância Verbal (livro 3, p. 236), a abordagem das regras de concordância é semelhante à do capítulo anterior, sem referência à variação presente especialmente nos textos escritos dos alunos, onde a ausência de plural nos verbos com sujeito plural é foco de muitas correções indicativas e resolutivas (RUIZ, 2015). Por outro lado, no subtítulo E Mais..., há novamente uma proposta de pesquisa de campo na qual devem ser coletadas dez frases que apresentem uma concordância diferente da normapadrão; quatro frases devem ser coletadas em textos escritos como "cartazes, faixas informativas, notícias, reportagens, entrevistas etc" (p. 257), e as demais, em gravações de fala espontânea.

A proposta de pesquisar os usos variáveis de concordância verbal em diferentes gêneros textuais é relevante e necessária. No entanto, não há exposição teórica sobre esse fenômeno, como também não há informações suficientes que ajudem professores e alunos a pensarem de forma consistente sobre explicações sociais e linguísticas para tais usos. Não se faz também nessa atividade referência aos textos produzidos pelos discentes, pensando na necessidade de contextualizar conteúdos novos na experiência linguística dos aprendizes das normas padrão e culta envolvidos nesse ensino.

No cotidiano da escola e fora dele, os indivíduos sofrem rotulações por suas escolhas linguísticas, e muitos acabam por se julgarem incapazes de aprender o português ensinado ali e exigido pela sociedade. Problematizar questões de variação no ensino de concordância verbal e concordância nominal deveria fazer parte das aulas de língua portuguesa, a fim de produzir entre os aprendizes conhecimento sobre seus próprios usos, em busca de contribuir para a segurança linguística desses alunos, que precisam se sentir mais livres para tecer textos coerentes e críticos. 
Antunes (2003, p. 147) já há algum tempo discute que “o mito do 'falar certo', nos meios sociais letrados, está comumente associado à concordância" e que a insistência dessa abordagem nos leva a esquecer que as marcas de concordância funcionam, na verdade, como uma forma de estabelecer a progressão textual, dimensão desse conteúdo não explorada nas coleções de LD em geral.

O trabalho com a concordância nas atividades propostas no livro explora as regras da variedade culta do português, propondo exercícios de encontrar as palavras que estão adequadas ou inadequadas à linguagem culta. Exercícios assim já trazem um modelo a ser seguido, sem ao menos explicitar o porquê das atividades propostas, conscientizando a todos da função desses conhecimentos em suas práticas linguísticas.

Já o conteúdo de regência nominal e verbal é abordado pensando não somente em como é a regência "[d] os verbos que, na língua culta formal, apresentam diferentes regências associadas a diferentes significados", mas também como é a regência "[d]os verbos com uma determinada regência na língua culta e outra na língua coloquial” (livro 3, p. 259). Em seguida, há explicações teóricas sobre o funcionamento da regência nas duas variedades citadas para os verbos assistir, ir/chegar, obedecer/desobedecer, pagar, perdoar, preferir, visar, como podemos ver no fragmento abaixo:

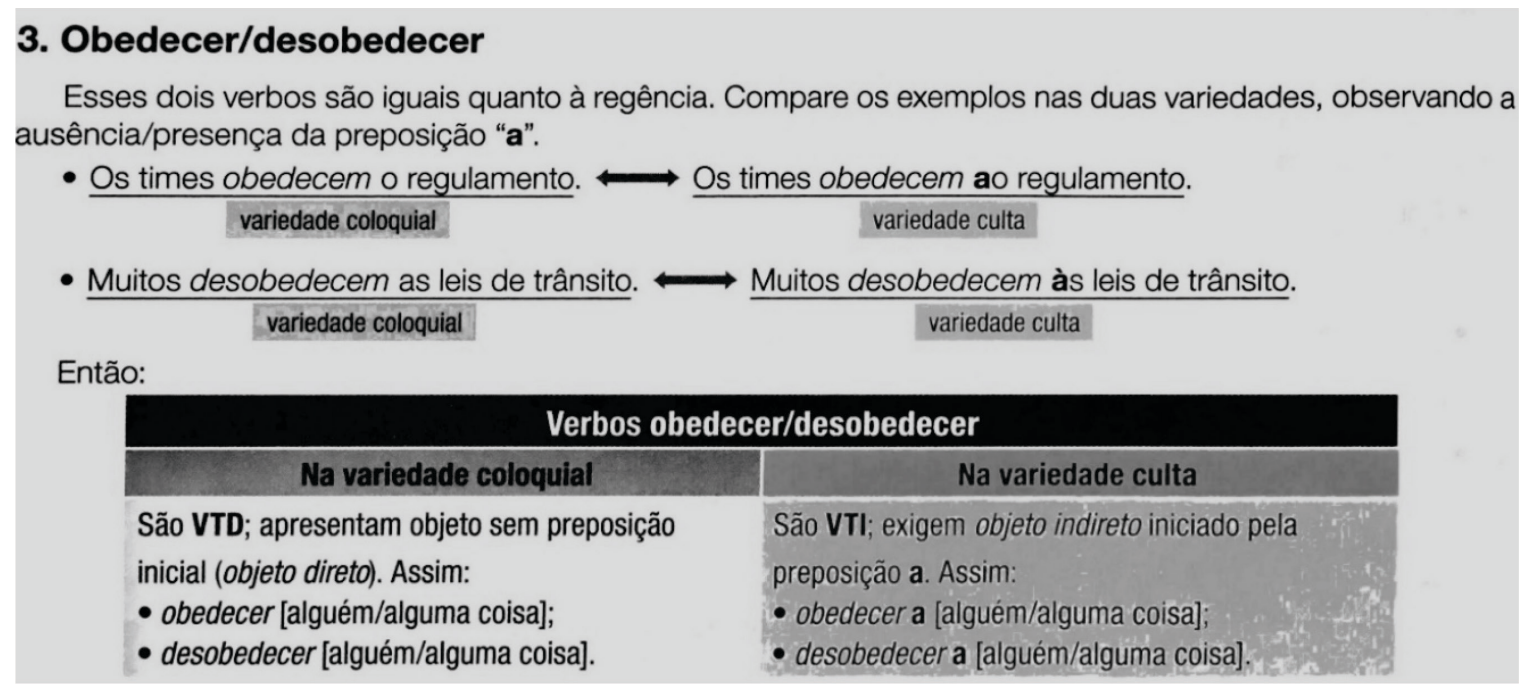

Figura 7: Exposição teórica de regência verbal (livro 3)

Fonte: Amaral et at. (2016, p. 264)

A coleção avança por dedicar espaço para a exposição teórica desses usos variáveis, ganhando mais consistência no ensino desse fenômeno gramatical. No entanto, falta uma argumentação problematizando essas diferenças linguísticas.

As prescrições normativas impostas aos usuários do português em relação aos verbos de movimento, por exemplo, têm exigido muito esforço e preocupação dos professores e vigilantes da língua pela ocorrência de estruturas do tipo "vamos na igreja”. Bagno (2004) debate essa questão de regência dos verbos de movimento explicando que o português é derivado do latim, e no latim havia a preposição "in" usada para indicar movimento (forma que corresponde ao nosso "em"), tendo este uso permanecido até a atualidade. Isso explica o fato de até hoje ser comum, no Brasil, o uso da preposição "em” com esses verbos, demonstrando a força de certos usos da língua que permanecem, mesmo com um trabalho de correção intenso por parte da escola, da sociedade.

Já analisando as atividades sobre esse conteúdo, vemos que é solicitado em sua maioria que os alunos justifiquem os usos adequados de regência, identifiquem usos da variedade coloquial, expliquem e reescrevam frases a fim de adequá-los à variedade culta do português, seguindo assim uma abordagem mais conservadora, já esperada para a seção denominada Atividades. 
É interessante que na seção Da teoria à prática (p. 278-280), em que a proposta, segundo os autores, é trabalhar com a funcionalidade dos elementos linguísticos no texto, no discurso, pensando na construção dos sentidos, há também a solicitação em um dos exercícios de reescrita de uma frase que contém uma forma não-padrão. A frase em questão é "Você é contra ou a favor de 15 bilhões para estádios de futebol”, na qual a expressão "de 15 bilhões para estádios de futebol” complementa tanto o termo "contra” (que não admite preposição "de") como "a favor" (que exige preposição "de”), ambos com regências diferentes. Essa frase foi escrita pelo jornalista e escritor Arnaldo Jabor no seu texto O plebiscito:

1. Leia o trecho abaixo e responda aos itens de a a c.

Você é contra ou a favor de 15 bilhões para estádios de futebol, dinheiro que dava para fazer 50 hospitais ou 75 quilômetros de metrô em São Paulo? Você é a favor da reforma política? Você sabe o que é voto distrital comum ou misto? É contra ou a favor? Aliás, você sabe o que é isso, filho?

JABOR, Arnaldo. O plebiscito. O Estado de S. Paulo, 9 jul. 2013. Caderno 2, p. C8.

a) Se tomarmos como parâmetro a norma-padrão, é possível identificar, na primeira pergunta do texto, uma inadequação relativa à regência nominal. Indique essa inadequação e comente-a.

b) Justifique o fato de o enunciador redigir o texto da forma como se apresenta.

c) Reescreva a primeira frase do texto, adequando-a à variedade culta formal.

Figura 8: Atividade (livro 3)

Fonte: Amaral et at. (2016, p. 279)

A solicitação de correção (letra "c") do uso intencional praticado por Jabor é feita apesar de ser pedido anteriormente (letra "b") que os alunos justifiquem tal escolha da forma não-padrão pelo produtor do texto, com a exposição para os professores da expectativa de resposta. Tal expectativa seria justamente os discentes concluírem na letra "b" "que o enunciador optou por uma construção coloquial, informal, típica da oralidade [mas usada na escrita]", que "contribui para maior concisão, dinamismo e vivacidade do questionamento do enunciador." (p. 279).

A solicitação feita na letra "c" nos faz refletir sobre a força da correção gramatical em nossa cultura escolar que possibilita essa escolha didática, a qual só se justifica por tentar satisfazer aos anseios normativistas. Com isso, é deixado de lado a incoerência de se solicitar a reescrita da frase em questão adequando-a à variedade culta formal. Não se considerou que o autor de tal frase a escreveu fazendo uso de seu conhecimento da língua e da sociedade, para se expressar de determinada forma em função de sua intencionalidade comunicativa.

\section{ALGUMAS CONSIDERAÇÕES}

Considerando o ensino de língua portuguesa, a tentativa de alguns pesquisadores e professores tem sido há algumas décadas de promover em sala de aula uma abordagem significativa dos conteúdos ministrados. Entretanto, parece-nos que não temos tido a habilidade de selecionar tais conteúdos, como também de tratá-los de modo consistente em nossos materiais didáticos e aulas, em função da ampliação da competência comunicativa do aluno.

Ao analisar a coleção Novas Palavras (2016), constatamos que, apesar de os capítulos específicos para abordar a variação linguística no livro 1 discutirem, entre outras questões, o fato de sabermos diversas regras gramaticais, as concepções de gramática, os tipos de variação, as diferentes variedades linguísticas, a coleção mantém um tratamento ainda inconsistente desse conteúdo e tradicional dos tópicos gramaticais tanto na exposição teórica como em muitos exercícios.

Nos capítulos dos livros 2 e 3 selecionados para serem analisados aqui, o ensino da heterogeneidade linguística proposto no livro 1 não se efetiva como tal, prevalecendo a crença de um padrão de língua sustentado no normativismo. Ou seja, não ocorre a 
continuidade da abordagem dada à variação linguística realizada no livro 1, ao tratar de tópicos gramaticais, justamente onde se faz muito necessário. Essa abordagem adotada pela coleção nos volumes 2 e 3 é incoerente com a que se propõe nos dois capítulos do livro 1, que traz avanços na discussão da variação linguística.

Outro ponto importante que fortalece nossa interpretação é a não realização de um trabalho de fato com a variação morfossintática, problematizando a heterogeneidade linguística a partir dos textos dos alunos. Com exceção de alguns exemplos, quadros e apontamentos curtos nos capítulos trabalhados dos livros 2 e 3, essa discussão perde em consistência teórica nas exposições sobre gramática.

A maneira como os LD abordam os tópicos gramaticais é um aspecto fundamental a ser observado nas coleções que chegam às escolas. Se sua abordagem ainda se sustenta numa concepção normativista de língua, apesar de avanços, isso nos leva a pensar que poderá continuar predominando nas aulas de português o estudo de nomenclaturas e classificações, com a prescrição da normapadrão sem um exercício de reflexão sobre os usos variáveis, sobre as regras de funcionamento da língua nos textos (Antunes, 2003).

As coleções de LD necessitam de um tratamento consistente e continuado do conteúdo variação linguística, a fim de dar suporte para os professores, já que esse material didático tem um papel central nos processos pedagógicos de ensino-aprendizagem da língua portuguesa.

Se não é construído no contexto escolar conhecimento sobre as variedades e suas variantes, especialmente discutindo as variantes não-padrão que ocorrem nos textos dos alunos e nos nossos também, o que é uma avaliação negativa dos falantes, o preconceito linguístico e sua consequência na segurança linguística das pessoas, corremos o risco de tratar superficialmente esse conteúdo tão desejado nos LD.

Finalizando, é importante destacar ainda que o PNLD (2018) avalia a abordagem da seção gramatical do LD em questão como tradicionalista na maior parte da coleção e com uma preocupação não sistemática com a variação linguística; um paradoxo quando se pensa no discurso tecido na sua Apresentação e nos dois capítulos do livro 1, Gramática... gramáticas e Noções de Variações Linguísticas.

\section{REFERÊNCIAS}

AMARAL, E. et al. Novas palavras. 3. ed., v. 1, 2 e 3. São Paulo: FTD, 2016.

ANTUNES, I. Aula de português: encontro e interação. São Paulo: Parábola Editorial, 2003.

BAGNO, M. Quando chegar em Americana, não sei o que vai ser: regências dos verbos ir e chegar com sentido de direção. In: BAGNO, M. Português ou brasileiro?: Um convite à pesquisa. São Paulo: Parábola, 2004. p. 139-150.

BAGNO, M. A variação linguística nos livros didáticos. In: BAGNO, M. Nada na língua é por acaso: por uma pedagogia da variação linguística. São Paulo: Parábola, 2007. p. 119-140.

BAKHTIN, M. A interação verbal. In: BAKHTIN, M. Marxismo e filosofia da linguagem. São Paulo: HUCITEC, 1990. p. $112-130$.

BORTONI-RICARDO, S. M. Heterogeneidade linguística e ensino da língua. In: BORTONI-RICARDO, S. M. Nós cheguemu na escola, e agora?: Sociolinguística e educação. São Paulo: Parábola, 2005. p. 13-17.

BORTONE, M. E.; ALVES, S. B. O fenômeno da hipercorreção. In: BORTONI-RICARDO, S. M. et al. Por que a escola não ensina gramática assim? São Paulo: Parábola, 2014. p. 205-216. 
BRASIL. Parâmetros Curriculares Nacionais (PCN+). Linguagens, códigos e suas tecnologias. Ensino médio. Brasília: MEC/SEF, 2002.p. 7-90.

BRASIL. Orientações Curriculares para o Ensino Médio (OCEM). Linguagens, códigos e suas tecnologias. Brasília: MEC/SEB, 2006. p. 5-45.

BRASIL. Programa Nacional do Livro Didático (PNLD) 2018: Língua portuguesa - Guia de livros didáticos - Ensino Médio. Brasília: MEC/SEB, 2017. p. 53-58.

CASTILHO, A. T. de. Diversidade do português brasileiro. In: CASTILHO, A. T. de. Nova gramática do português brasileiro. São Paulo: Contexto, 2010. p. 205-209.

FERREIRA, M. B. A linguagem e os processos de enunciação, dialogismo e polifonia. Olhar de professor, Ponta Grossa, v.7, n.1, p. 67-75, 2004.

GÖRSKI, E. M.; COELHO, I. L. Variação linguística e ensino de gramática. Work. pap. linguíst., Florianópolis, v. 10, n. 1, p. 73-91, jan./jun. 2009.

MILROY, J. Ideologias linguísticas e as consequências da padronização. In: LAGARIS, X. C.; BAGNO, M. (org.). Políticas da norma e conflitos linguísticos. São Paulo: Parábola, 2011.p. 49-85.

RUIZ, E. D. A correção (o turno do professor): uma leitura. In: RUIZ, E. D. Como corrigir redações na escola. Contexto: São Paulo, 2015. p. 33-57.

SANTOS, A. S. dos; BORGES, C. L. C. Variação linguística e ensino: uma abordagem sobre os livros didáticos de português. In: CONGRESSO NACIONAL DE LINGUÍSTICA E FILOLOGIA, 15, 2011, Rio de Janeiro. Anais... Rio de Janeiro: Instituto de Letras da Universidade do Estado do Rio de Janeiro, 2011. p. 1006-1016.

TRAVAGLIA, L. C. Questões fundamentais para o ensino de gramática. In: TRAVAGLIA, L. C Gramática e interação: uma proposta para o ensino de gramática no $1^{\circ}$ e $2^{\circ}$ graus. São Paulo: Cortez, 2009. p. 15-66.

\section{(1) $\circledast \circledast$}

